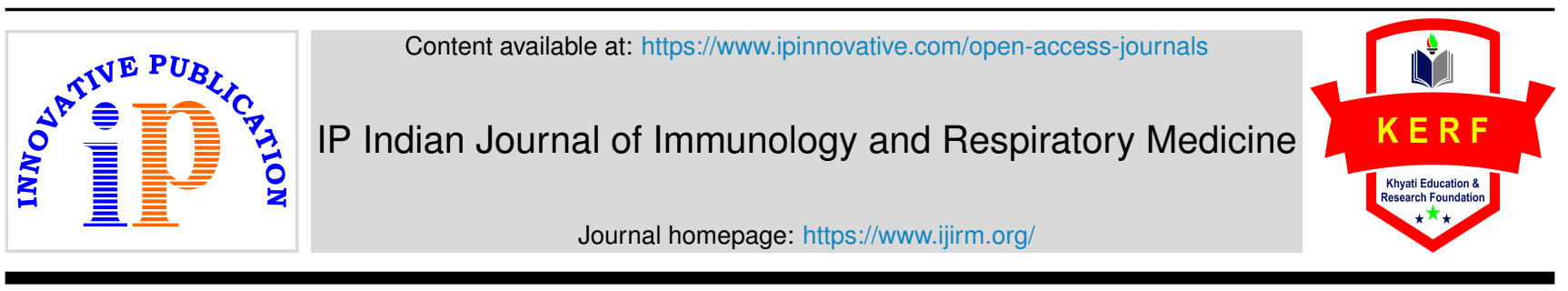

\title{
Editorial
}

\section{The new variant of severe acute respiratory syndrome coronavirus 2- A grave situation in a pandemic}

\author{
Sankalp Yadav ${ }^{1} *$, Gautam Rawal ${ }^{2}$ \\ ${ }^{1}$ Dept. of Medicine \& Tuberculosis, Shri Madan Lal Khurana Chest Clinic, Moti Nagar, NDMC, New Delhi, India \\ ${ }^{2}$ Dept. of Respiratory Intensive Care, Max Super Specialty Hospital, Saket, New Delhi, India
}

\section{A R T I C L E I N F O}

Article history:

Received 01-02-2021

Accepted 16-02-2021

Available online 25-02-2021

\begin{abstract}
(C) This is an open access article distributed under the terms of the Creative Commons Attribution License (https://creativecommons.org/licenses/by/4.0/) which permits unrestricted use, distribution, and reproduction in any medium, provided the original author and source are credited.
\end{abstract}

The pandemic of severe acute respiratory syndrome coronavirus 2 (SARS-CoV-2) has led to a never seen before devastation of mankind. ${ }^{1}$ The disease i.e., the coronavirus disease 2019 (COVID-19) has so far resulted in largescale mortality and morbidity. ${ }^{2}$ The data till $16^{\text {th }}$ February 2021, suggested that there were 109,751,117 laboratoryconfirmed cases of COVID-19 infection globally, with $2,420,616$ reported deaths and 84,310,929 recoveries. ${ }^{3}$ This data proves that the COVID-19 is a considerable biological hazard and is a worldwide threat. ${ }^{4}$ The disease which originated in Wuhan, China has spared no one from any country in the world. ${ }^{2}$ This pandemic is remarkable not only because of the fatalities it has caused to date but due to the psychological and other impacts it had on the human population which are long-lasting and even more dangerous. ${ }^{5}$ The researchers have worked tirelessly to find a vaccine for this disease and have achieved great success by developing various vaccines. ${ }^{6}$ However, the reports of a new variant of this SARS-CoV-2 has instilled fear among the general public.

SARS-CoV-2 is an enveloped RNA virus, these viruses have an unusually high mutation rates because their replication enzyme are susceptible to errors when making new virus copies. ${ }^{7}$ The first reports of a dominant new variant of SARS-CoV-2 came from the southern UK. ${ }^{8,9}$

\footnotetext{
* Corresponding author.

E-mail address: drsankalpyadav@gmail.com (S. Yadav).
}

Where a fast-spreading variant, named VUI 202012/01 and later known as B-1.1.7 was identified in December. ${ }^{9,10}$ This variant has been detected in China, Australia, Italy, the Netherlands, and some other countries, as well as some parts of the US. ${ }^{8,9}$ The initial workup on this strain showed that it is a result of antigenic drift with 17 accumulated mutations and is seventy percent more transmissible than the already circulating original form of the virus. ${ }^{11,12}$ Out of these 17 mutations, eight are on the spike protein: the portion of the coronavirus's shell that allows this virus to bind to receptors on host cell surfaces and thus infecting these cells. $^{11}$ The first detection of the mutation from the UK could be attributed to its strong viral surveillance program wherein the country tries to analyze genetic sequences of ten percent of all new cases and compare them to spot any changes. ${ }^{8,11}$ However, no such noteworthy centralized efforts are evident anywhere in the world. ${ }^{11}$

The new variant has mutations that affect one of three genomic targets used by some PCR tests. ${ }^{8}$ Thus implying that in those PCR tests, that target this area would emerge negative. ${ }^{8}$ But as the PCR tests generally detect more than one gene target, thus, a mutation in the spike protein only somewhat affect the test, ultimately lowering the risk of false-negative results. ${ }^{8}$

However, as per the UK Health Agency Public Health England, this new variant of SARS-CoV-2 is similar to the already existing original virus strain when compared for 
the requirement of hospital admissions, disease severity, or mortality. ${ }^{12}$ The new strain is also vaccine susceptible and is does not have the vaccine escape capability. ${ }^{13}$ Furthermore, there are some unconfirmed reports based on preliminary evidence suggestive of higher mortality with the new variant. ${ }^{9}$ Anyways, the increased infectiousness of the new variant of the SARS-CoV-2 will result in a higher number of COVID-19 cases, and thus when it was expected that a plummet in case-load may occur due to the vaccines against this virus, a surge in cases might be seen which would ultimately overwhelm the healthcare systems around the world. ${ }^{12}$

Also, there are reports from South Africa which is currently facing a second surge of COVID-19 cases, due to a new variant of SARS-CoV-2 known as, B.1.351. ${ }^{9}$ This variant has been known to evade the body's immune response and is detected in samples as early as October $2020 .{ }^{9}$ It has a better binding capacity than the original virus and is due to a mutation in the spike protein, called N501 $\mathrm{Y}^{11}$ Theoretically, a better binding means higher transmissibility. ${ }^{11}$

In the US another spike protein mutation, called D614G has been seen, which allows the virus to replicate better in the upper respiratory tract of mice rather than the lower tract. ${ }^{11}$ Thereby allowing the virus to spread more easily through sneezing and coughing. ${ }^{11}$ This D614G variant has been circulating for some time, however, and it has not been proved to be comparatively more infectious or to cause more serious symptoms. ${ }^{11}$

The impact of mutations in spike proteins could probably be on the vaccines in a similar way as the flu vaccines are affected where there is a need for a new vaccine every year due to mutations in the flu virus. ${ }^{11}$ The current vaccines may, after an extended period of time, become somewhat less effective. ${ }^{11}$ Thus forcing the vaccine developers to work for a broad spectrum action on various mutated versions of SARS-CoV-2. ${ }^{11}$

Toconclude, the pandemic of COVID-19 has affected the lives of human beings. The appearance of new mutants of the SARS-CoV-2 has only resulted in fear and insecurity. With the availability of vaccines against the virus, it is imperative to vaccinate the majority of the human population to avoid the ever-increasing morbidity and mortality. The governments and planning agencies should ensure faster and countrywide vaccine programs for better results. The vaccine developers should increase the efforts to widen the effectiveness of already existing vaccines and war front efforts should be made to develop new treatment options and vaccines.

\section{Acknowledgement}

None.

\section{Source of Funding}

No financial support was received for the work within this manuscript.

\section{Conflict of Interest}

The authors declare that they have no conflict of interest.

\section{References}

1. Korber B, Fischer WM, Gnanakaran S, Yoon H, Theiler J, Abfalterer $\mathrm{W}$, et al. Tracking changes in SARS-CoV-2 Spike: Evidence that D614G increases infectivity of the COVID-19 virus. Cell. 2020;182(4):812-27.e19. doi:10.10/6/1.cell.2020.06.043.

2. Yadav S, Rawal G. The case of pulmonary tuberculosis with COVID-19 in an Indian male-a first of its type case ever reported from South Asia. Pan Afr Med J. 2020;36:374. do1:10.11604/pamj.2020.36.374.24260.

3. Coronavirus cases. Available from URL:- https://www.worldometers. info/coronavirus/. Last accessed 2021 on February 16.

4. Dawood AA. Mutated COVID-19 may foretell a great risk for mankind in the future. New Microbes New Infect. 2020;35:100673. do1:10.1016/1.nmn1.2020.100673.

5. Yadav S, Rawal G. The mental health status of the general public and healthcare professionals in the COVID-19 pandemic. IP Indian $J$ Immunol Respir Med. 2020;5(2):72-4. [01:10.18231/].1]11rm.2020.032

6. Yadav S, Rawal G. The coronavirus disease 2019 vaccineA step to halt the devastation by the pandemic of SARSCoV-2. IP Indian J Immunol Respir Med. 2020;5(4):196-7. [01:10.18231/].1]1rm.2020.057.

7. Hewings-Martin Y. Is there more than one strain of the new coronavirus? Available from URL:- https://www.medicalnewstoday .com/articles/is-there-more-than-one-strain-of-the-new-coronavirus. Last accessed 2021 on February 12.

8. Reuters. Explained: The new coronavirus variant in Britain. Available from URL:- https://www.thehindu.com/sci-tech/science/explained -the-new-coronavirus-variant-in-britain/article33391694.ece. Last accessed 2021 on February 12

9. WSJ. New Covid-19 strains: What scientists know about coronavirus variants. Available from URL:- https://www.wsj.com/articles/new-co vid-19-strains-what-scientists-know-about-coronavirus-variants-1160 9466017. Last accessed 2021 on February 12.

10. Reuters. New coronavirus strain spreading in UK has key mutations, scientists say. Available from URL:- https://www.thehindu.com/sci-te $\mathrm{ch} /$ science/new-coronavirus-strain-spreading-in-uk-has-key-mutation s-scientists-say/article33337530.ece. Last accessed 2021 on February 12.

11. Reardon S. The U.K. coronavirus mutation is worrying but not terrifying. Available from URL:- https://www.scientificamerican.com /article/the-u-k-coronavirus-mutation-is-worrying-but-not-terrifying/. Last accessed 2021 on February 12.

12. Kirby T. New variant of SARS-CoV-2 in UK causes surge of COVID-

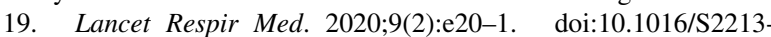
2600(21)00005-9.

13. Tang JW, Tambyah PA, Hui DSC. Emergence of a new SARS-CoV-2 variant in the UK. Journal of Infection. Available from URL:- https:// www.journalofinfection.com/article/S0163-4453(20)30786-6/fulltext . Last accessed 2021 on February 12. DOI:10.1016/j.jinf.2020.12.024 2020

Cite this article: Yadav S, Rawal G. The new variant of severe acute respiratory syndrome coronavirus $2-\mathrm{A}$ grave situation in a pandemic. $I P$ Indian J Immunol Respir Med 2021;6(1):1-2. 